\title{
Survivin Inhibitors Mitigate Chemotherapeutic Resistance in Breast Cancer Cells by Suppressing Genotoxic Nuclear Factor- $\kappa \mathrm{B}$ Activation $\$$
}

\author{
Wei Wang, Bo Zhang, Arul M. Mani, Zhongzhi Wu, Yu Fan, Wei Li, and Zhao-Hui Wu \\ Departments of Pathology and Laboratory Medicine (W.W., B.Z., Z.-H.W.), Physiology (A.M.M.), and Pharmaceutical Sciences \\ (Z.W., W.L.), Center for Cancer Research (W.W., B.Z., Z.-H.W.), University of Tennessee Health Science Center, Memphis, \\ Tennessee; and Cancer Institute, Affiliated People's Hospital of Jiangsu University, Zhenjiang, Jiangsu, China (Y.F.)
}

Received March 14, 2018; accepted April 30, 2018

\begin{abstract}
Therapeutic resistance developed after chemotherapy and aggressive metastasis are the major causes of cancer-related death in patients with triple-negative breast cancer (TNBC). Survivin is the smallest member of the inhibitor-of-apoptosis proteins (IAPs) family, which plays critical roles in cell division and cell survival. High expression levels of survivin have been associated with therapeutic resistance in various cancers. We recently developed a novel small-molecule survivin inhibitor mimicking the IAP-binding motif of second mitochondriaderived activator of caspase, which showed high potency in promoting survivin degradation. Here, we show that survivin inhibitor MX106/MX107 suppresses TNBC cell proliferation. Moreover, MX106/MX107 synergized with chemotherapeutic drugs or radiation and significantly enhanced tumoricidal efficacy of
\end{abstract}

genotoxic treatments. Mechanistically, MX106/MX107 induced degradation of XIAP and/or cIAP1, which inhibited nuclear factor $\kappa \mathrm{B}(\mathrm{NF}-\kappa \mathrm{B})$ activation by genotoxic agents. Treatment with MX106/MX107 alone did not activate alternative NF- $\kappa$ B signaling in breast cancer cells, which is likely attributable to their selective potency in degrading survivin in these cells. In addition, survivin degradation by MX106/MX107 dramatically increased abnormal mitotic spindle formation and cell division failure, which led to cell cycle arrest in breast cancer cells. Overall, our study suggests that combination treatment of TNBC using survivin inhibitors MX106/MX107 with cytotoxic chemotherapeutic drugs can achieve significantly improved therapeutic efficacy, which depends on MX106/MX107-mediated inhibition of genotoxic $\mathrm{NF}-\kappa \mathrm{B}$ activation.

\section{Introduction}

Triple-negative breast cancer (TNBC) is a heterogenic breast cancer subtype that lacks hormone receptors (estrogen receptor/progesterone receptor) and human epidermal growth factor receptor 2 . In the absence of approved molecular targeted therapy, cytotoxic chemotherapy remains the standard of care for treating patients with TNBC (Bianchini et al., 2016). Although most patients with TNBC respond to chemotherapy initially, many develop drug resistance and suffer

This work was supported in part by the National Institutes of Health National Cancer Institute [Grants R01-CA149251 (to Z.-H.W.) and R01CA193609 (to W.L.)], the National Natural Science Foundation of China [Grant 81528016], the American Cancer Society [Grant RSG-13-186-01-CSM], and the Jiangsu Provincial Key R\&D Special Fund [Grant BE2015666].

https://doi.org/10.1124/jpet.118.249151.

S This article has supplemental material available at jpet.aspetjournals.org. rapid relapse within 2 to 3 years after the initial treatment. Moreover, TNBC is characterized by aggressive invasion and a unique pattern of metastases, which may further contribute to the drug resistance developed in these patients (Foulkes et al., 2010). More effective treatments and novel approaches to mitigate drug resistance are urgently needed to improve the clinical outcome of these patients.

A variety of molecular mechanisms have been demonstrated to promote therapeutic resistance, among which transcription factor nuclear factor $\kappa \mathrm{B}(\mathrm{NF}-\kappa \mathrm{B})$ was found to play critical roles in mediating both intrinsic and acquired therapeutic resistance in cancer cells (Nakanishi and Toi, 2005; Baldwin, 2012; Holohan et al., 2013). Activation of NF- $\kappa$ B promotes cell proliferation, inhibits apoptosis, and drives the inflammatory microenvironment, which all could contribute to cancer progression and therapeutic resistance. In addition, crosstalk

\footnotetext{
ABBREVIATIONS: BV6, (2S)-1-[(2S)-2-cyclohexyl-2-[[(2S)-2-(methylamino)propanoyl]amino]acetyl]-N-[(2S)-1-[6-[[(2S)-2-[[(2S)-1-[(2S)-2-cyclohexyl-2[[(2S)-2-(methylamino)propanoyl]amino]acetyl]pyrrolidine-2-carbonyl]amino]-3,3-diphenylpropanoyl]amino]hexylamino]-1-oxo-3,3-diphenylpropan-2-yl]pyrrolidine-2-carboxamide; Cl, combination index; Dox, doxorubicin; DTT, dithiothreitol; HEK293, human embryonic kidney 293; IAP, inhibitor-of-apoptosis proteins; IL, interleukin; IP, immunoprecipitation; IR, ionizing radiation; MX-106, 5-((4-iospropylbenzyl)oxy) methyl)-7-(pyrrolidin-1-ylmethyl)quinolin-8-ol; MX-107, 5-(((4-ethylbenzyl)oxy)methyl)-7-(pyrrolidin-1-ylmethyl)quinolin-8-ol; NEMO, NF- $\kappa \mathrm{B}$ essential modulator; NF- $\kappa$, nuclear factor $\kappa \mathrm{B}$; PARP, poly(ADP-ribose) polymerase; SMAC, second mitochondria-derived activator of caspases; TNBC, triple-negative breast cancer; TNF $\alpha$, tumor necrosis factor $\alpha$; UC-112, 5-[(phenylmethoxy)methyl]-7-(1-pyrrolidinylmethyl)-8-quinolinol; VP16, (5S,5aR,8aR,9R)-5-[[(2R,4aR,6R,7R,8R,8aS)-7,8-dihydroxy-2-methyl-4,4a,6,7,8,8a-hexahydropyrano[3,2-d] [1,3]dioxin-6-yl]oxy]-9-(4-hydroxy-3,5-dimethoxyphenyl)-5a,6,8a,9-tetrahydro-5H-[2]benzofuro[6,5-f][1,3]benzodioxol-8-one; YM155 [1(2-methoxyethyl)-2-methyl-3-(pyrazin-2-ylmethyl)-2H-benzo[f]benzimidazole-4, 9-dione; bromide.
} 
between NF- $\kappa \mathrm{B}$ with other signaling cascades, including the Janus kinase/signal transducer and activator of transcription proteins, Wnt $/ \beta$-catenin, and transforming growth factor $\beta$ pathways, further facilitates the development of drug resistance by promoting epithelial-mesenchymal transition and self-renewal of the tumor-initiating cell/cancer stem-like cell population (Singh and Settleman, 2010; Mitra et al., 2015; Zheng, 2017). Our previous studies revealed a retrograde nuclear-to-cytoplasmic signaling cascade that mediates DNA damaging agent-induced $\mathrm{NF}-\kappa \mathrm{B}$ activation (Wu and Miyamoto, 2007; McCool and Miyamoto, 2012). In this genotoxic $\mathrm{NF}-\kappa \mathrm{B}$ signaling pathway, the NF- $\kappa \mathrm{B}$ essential modulator NEMO (also known as I $\kappa$ B kinase/IKK $\gamma$ ) functions as the messenger to relay nuclear DNA damage signaling into cytoplasmic NF- $\kappa \mathrm{B} / \mathrm{IKK}$ machinery through its sequential modification such as sumoylation, phosphorylation, and ubiquitylation (Huang et al., 2003; Wu et al., 2006, 2010). Moreover, we and other laboratories also identified a number of critical regulators, such as Ataxia Telangiectasia Mutated (ATM), Protein inhibitor of activated STAT y (PIASy), cIAP1, poly(ADP-ribose) polymerase 1 (PARP1), TNF receptor associated factor 6 (TRAF6), XIAP1, ELKS (protein rich in the amino acids E, L, K and S), and SAM68 (the Src-Associated substrate in Mitosis of $68 \mathrm{kDa}$ ), which play essential roles in modulating this genotoxic NF- $\kappa \mathrm{B}$ signaling pathway (Mabb et al., 2006; Jin et al., 2009; Stilmann et al., 2009; Hinz et al., 2010; Wu et al., 2010; Fu et al., 2016). In response to chemotherapeutic treatments or radiation, this atypical $\mathrm{NF}-\kappa \mathrm{B}$ signaling cascade is activated in cancer cells, which enhances the transcription of a variety of protein-coding genes and microRNAs, promoting drug resistance and invasiveness of cancer cells (McCool and Miyamoto, 2012; Niu et al., 2012, 2013, 2016).

Survivin (BIRC5) is the smallest member of the inhibitor-ofapoptosis proteins (IAPs) family, which also includes cIAP1/2 and XIAP. Survivin expression is frequently increased in various cancers and has been associated with chemoresistance and poor prognosis in patients with cancer (Altieri, 2015; Peery et al., 2017). The oncogenic roles of survivin mainly depend on its function in inhibiting apoptosis and as a key mitotic regulator (Altieri, 2015; Garg et al., 2016). In normal cells, survivin expression is abundant during the embryonic and fetal development stages. In contrast, the survivin level becomes almost undetectable in terminally differentiated adult cells (Altieri, 2015). Therefore, the increased expression of survivin in most cancer cells makes it an attractive cancerspecific target for cancer treatment. We recently developed and optimized a potent small-molecule inhibitor of survivin based on a tetrapeptide motif (AVPI) harbored in the endogenous IAP antagonist, second mitochondria-derived activator of caspases (SMAC) (Wang and Li, 2014; Xiao and Li, 2015; Xiao et al., 2015). We found that this small-molecule inhibitor, UC-112 (5-[(phenylmethoxy)methyl]-7-(1-pyrrolidinylmethyl)-8-quinolinol), and its derivatives, MX106 (5-((4-iospropylbenzyl)oxy)methyl)-7(pyrrolidin-1-ylmethyl)quinolin-8-ol) and MX107 (5-(((4-ethylbenzyl) oxy)methyl)-7-(pyrrolidin-1-ylmethyl)quinolin-8-ol), efficiently induced proteasome-dependent degradation of survivin in a number of cancer cell lines. In addition to survivin, these small molecules also promoted degradation of other IAPs, such as cIAP1/2 and XIAP, with reduced potency and in a cell type-dependent manner. Moreover, we showed that our survivin inhibitors significantly reduced melanoma cell growth in vitro and in a xenograft mouse model, suggesting their potential antimelanoma efficacy (Wang and Li, 2014; Xiao et al., 2015).

Here we show that survivin inhibitor MX106/MX107 suppresses TNBC cell growth in vitro and in an orthotopic xenograft model. Moreover, MX106 showed robust synergism with chemotherapeutics and ionizing radiation (IR) in inhibiting proliferation and promoting apoptosis in cancer cells. Mechanistically, MX106/MX107 suppressed DNA damage-induced NF- $\kappa$ B activation, which depends on degradation of cIAP1 and XIAP. In contrast, survivin is not required for genotoxic NF- $\kappa \mathrm{B}$ activation, whereas its depletion leads to cell cycle arrest and mitotic catastrophe in TNBC cells. We further found that the combination treatment of a survivin inhibitor with doxorubicin (Dox) efficiently reduced TNBC xenograft tumor growth with significantly increased tumorsuppressive efficacy compared with either drug alone. Our results suggest that a small-molecule survivin inhibitor may also be used for treating TNBC, especially in combination with cytotoxic chemotherapeutics. This combinatory regimen remarkably reduced drug resistance developed in TNBC cells by inhibiting NF- $\kappa \mathrm{B}$, which sensitized TNBC cells to a lower dose of Dox treatment with improved efficacy.

\section{Materials and Methods}

Cells, Plasmids, and Regents. Human embryonic kidney 293 (HEK293) T cells, human breast cancer MDA-MB-231 cells, and human bone osteosarcoma U2OS cells were obtained from American Type Culture Collection (Manassas, VA) and cultured in Dulbecco's modified Eagle's medium supplemented with $10 \%$ fetal bovine serum. Both MDA-MB-231 and U2OS cells were derived from females. Cells resuscitated from the original passage and passaged within 6 months were used in all experiments. The cell lines from American Type Culture Collection were characterized by short tandem repeat profiling. The Myc-NEMO plasmid was generated by cloning the human NEMO coding sequence into the pcDNA3 vector as reported previously (Wu et al., 2006). Compounds MX106 and MX107 (previously denoted as compounds $4 \mathrm{~g}$ and $4 \mathrm{f}$, respectively) were synthesized and characterized as previously reported (Xiao et al., 2015). Etoposide [VP16; $(5 S, 5 a R, 8 a R, 9 R)-5$-[[(2R,4aR,6R,7R,8R,8aS)-7,8-dihydroxy-2methyl-4,4a,6,7,8,8a-hexahydropyrano[3,2-d][1,3]dioxin-6-yl]oxy]-9-(4hydroxy-3,5-dimethoxyphenyl)-5a,6,8a,9-tetrahydro-5H-[2]benzofuro $[6,5-f][1,3]$ benzodioxol-8-one] and Dox were purchased from SigmaAldrich (St. Louis, MO).

Combination Index Calculation. The effect of the combination of Dox with MX106 was determined by the CompuSyn program (ComboSyn). Drug concentrations were designed based on the $\mathrm{IC}_{50}$ value of each drug tested. Synergism, additive activity, or antagonism was determined by the Chou-Talalay method (Chou, 2010) and calculated with a combination index (CI) using CompuSyn software.

Immunofluorescence. Cells were seeded on glass coverslips and treated with MX106 or dimethylsulfoxide for 24 hours. Then treated cells were fixed with $4 \%$ paraformaldehyde for 15 minutes, followed by permeabilization with $0.2 \%$ Triton X-100 for 5 minutes. Cells then were blocked with $3 \%$ bovine serum albumin for 15 minutes, incubated with the primary antibody ( $\alpha$-tubulin) for 1 hour, and then incubated with fluorescence-conjugated secondary antibody for 1 hour. Finally, cells were imaged with a fluorescent microscope (Invitrogen, Carlsbad, CA). Nuclei were visualized by $4^{\prime}, 6$-diamidino-2-phenylindole staining.

Immunoprecipitation and Detection of Ubiquitylation. Briefly, cells were lysed with $1 \%$ SDS in immunoprecipitation (IP) lysis buffer [ $20 \mathrm{~mm}$ Tris, $\mathrm{pH}$ 7.0, $250 \mathrm{~mm} \mathrm{NaCl}, 3 \mathrm{~mm}$ EDTA, $3 \mathrm{~mm}$ EGTA, $0.5 \%$ Nonidet P-40, $2 \mathrm{~mm}$ dithiothreitol (DTT), $0.5 \mathrm{~mm}$ phenylmethylsulfonyl fluoride, $20 \mathrm{~mm} \beta$-glycerol phosphate, $1 \mathrm{~mm}$ sodium 
A

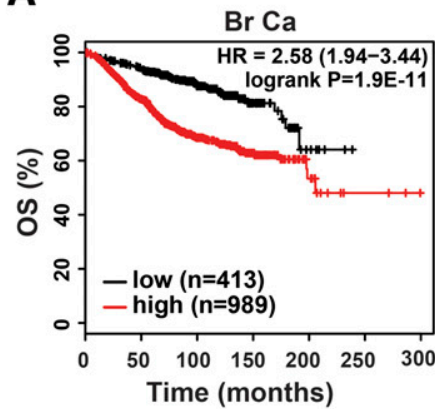

C

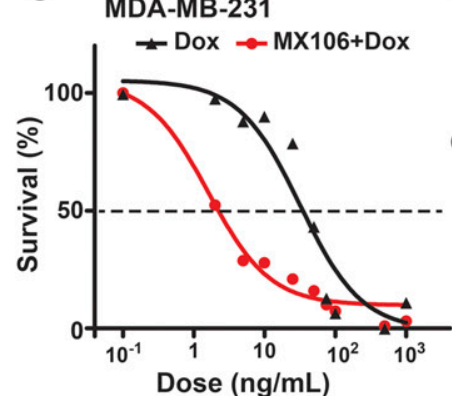

TNBC

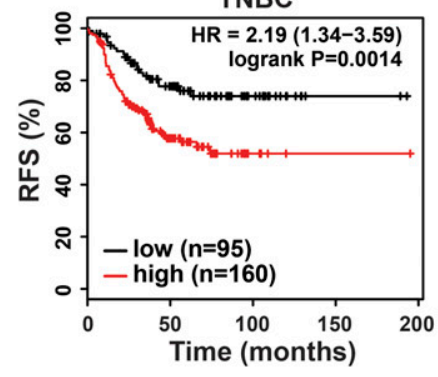

B

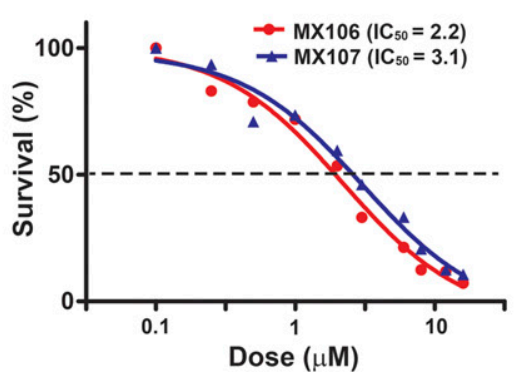

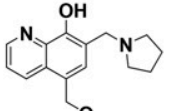

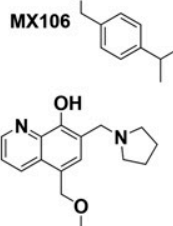

MX107
D

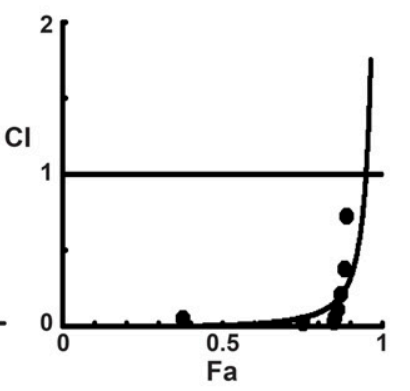

E

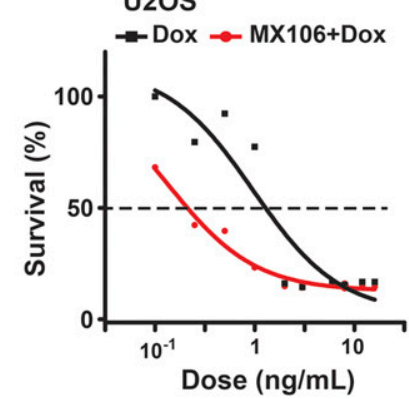

$\mathbf{F}$

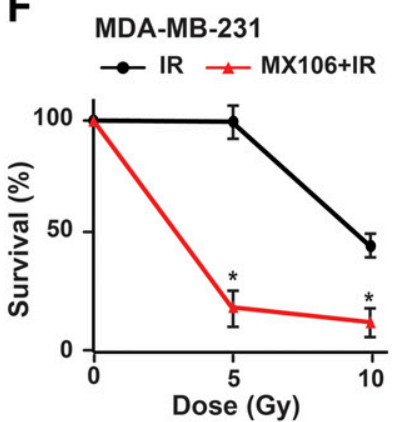

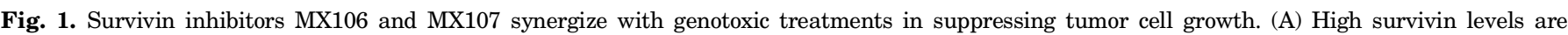

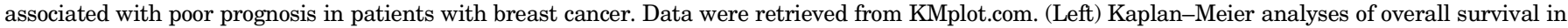

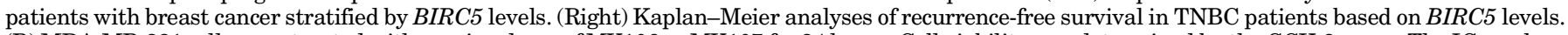

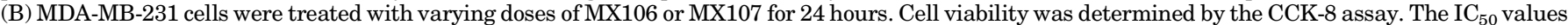

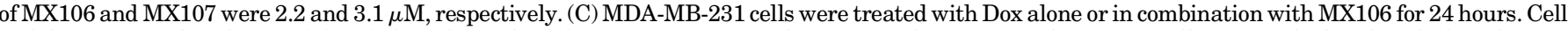

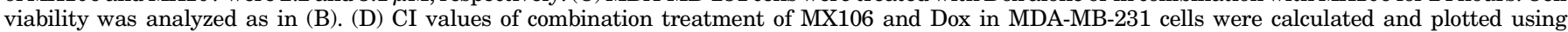

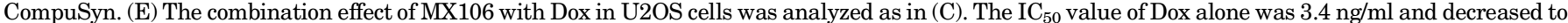

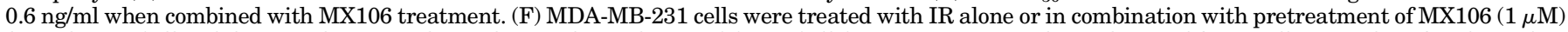

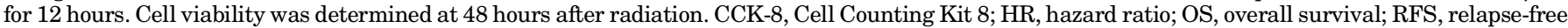
survival.

orthovanadate, $1 \mu \mathrm{g} / \mathrm{ml}$ leupeptin, $1 \mu \mathrm{g} / \mathrm{ml}$ aprotinin, $10 \mathrm{~mm} p$-nitrophenyl phosphate, and $10 \mathrm{~mm}$ sodium fluoride] at $95^{\circ} \mathrm{C}$ for 30 minutes. The cell lysates were then diluted with IP lysis buffer to reduce SDS to $0.1 \%$ and were mixed with primary antibodies and protein G-Sepharose for incubation at $4^{\circ} \mathrm{C}$ overnight. The precipitated proteins were resolved on SDA-PAGE and the ubiquitylation of precipitated proteins was examined by immunoblotting.

In Vitro Kinase Assay. A total of $2 \times 10^{6}$ cells were treated as indicated. Cell pellets were lysed in $10 \%$ phosphate-buffered saline and $90 \%$ IP lysis buffer (20 mM Tris, $\mathrm{pH} 7.0,250 \mathrm{mM} \mathrm{NaCl}, 3 \mathrm{mM}$ EDTA, $3 \mathrm{mM}$ EGTA, 0.5\% NP-40, $2 \mathrm{mM}$ DTT, $0.5 \mathrm{mM}$ phenylmethylsulfonyl fluoride, $20 \mathrm{mM} \beta$-glycerol phosphate, $1 \mathrm{mM}$ sodium orthovanadate, $1 \mu \mathrm{g}$ leupeptin/ml, $1 \mu \mathrm{g}$ aprotinin/ml, $10 \mathrm{mM} p$-nitrophenyl phosphate, and $10 \mathrm{mM}$ sodium fluoride). Supernatants were diluted further in lysis buffer, and $1 \mu \mathrm{g} \alpha$-TAB2 antibody (TAK1 KA) or $\alpha$-IKK $\gamma$ antibody (IKK KA) was added to each tube. Protein G-Sepharose-enriched IP samples were washed three times in lysis buffer and three times in TAK1 kinase buffer (50 mM Tris-HCl, pH 7.5, $0.5 \mathrm{mM}$ DTT, $5 \mathrm{mM} \mathrm{MgCl}_{2}, 50 \mu \mathrm{M}$ ATP) or IKK kinase buffer (20 mM HEPES, pH 7.7, $2 \mathrm{mM} \mathrm{MgCl} 2,2 \mathrm{mM} \mathrm{MnCl}_{2}, 1 \mathrm{mM}$ DTT, and $10 \mu \mathrm{M} \mathrm{ATP}$ ) supplemented with the panel of inhibitors as above. Kinase activity was assayed in the respective kinase buffer with $1 \mu \mathrm{g}$ substrate (glutathione $S$-transferase/IKK $\beta 166-197$ for TAK1 KA, and glutathione $S$-transferase $/ \mathrm{I} \kappa \mathrm{B} \alpha 1-56$ for IKK KA) and $1 \mu \mathrm{Ci}[\gamma$-32P] ATP for 45 minutes at $30^{\circ} \mathrm{C}$. The samples were boiled in $2 \times$ SDS loading buffer, separated by SDS-PAGE, and transferred to polyvinylidene fluoride membranes. Radioactive signals were captured by Phosphoimage screening and analyzed by ImageQuant software (GE Healthcare Life Sciences, Pittsburgh, PA). The membranes were subjected to Western blotting.

In Vivo Xenograft Model. Female NOD scid $\gamma$ mice (aged 6 weeks) from Jackson Laboratory (Bar Harbor, ME) were maintained at the University of Tennessee Health Science Center animal facility.
All animal studies were conducted in accordance with National Institutes of Health animal use guidelines and were approved by the University of Tennessee Health Science Center Institutional Animal Care and Use Committee. $1 \times 10^{6}$ MDA-MB-231 LM2 cells were injected into the mouse mammary fat pad (two/each mouse). Tumor growth was monitored by caliper measurement using the following formula: (width ${ }^{2} \times$ length/2) (cubic millimeter). When the tumor volume reached approximately $100 \mathrm{~mm}^{3}$, tumor-bearing mice were randomly divided into four groups and treated with intraperitoneal injection of phosphate-buffered saline vehicle, Dox $(1.5 \mathrm{mg} / \mathrm{kg}$, once a week, every Monday), MX106 (20 mg/kg per day, 5 days per week, Monday through Friday), or a combination of Dox and MX106 (same dosage and schedule as the single treatment). At the end point, the mice were sacrificed and primary tumors were isolated for further analyses. Group assignment and tumor monitoring were carried out double blinded. Mice were also imaged by the Xenogen IVIS system (PerkinElmer, Waltham, MA) to visualize primary tumors and lung metastases.

Statistical Analysis. The results are presented as means \pm S.D. and were analyzed with one-way analysis of variance or the $t$ test. Disease-free survival/overall survival analysis was estimated by the Kaplan-Meier method. All statistical analyses were performed using SPSS 22.0 software (SPSS Inc., Chicago, IL). $P<0.05$ was denoted as statistically significant.

\section{Results}

Survivin Inhibitors Sensitize Cancer Cells to Genotoxic Treatments. Increased survivin expression was found in various stages of breast cancer tissues compared with normal breast tissues (Ryan et al., 2005). Higher survivin 
A

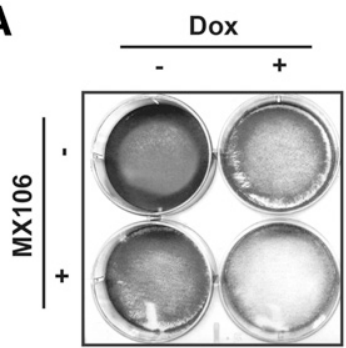

\section{C $\quad$ HEK293}

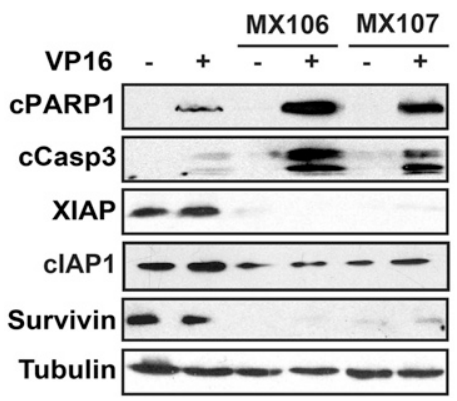

B

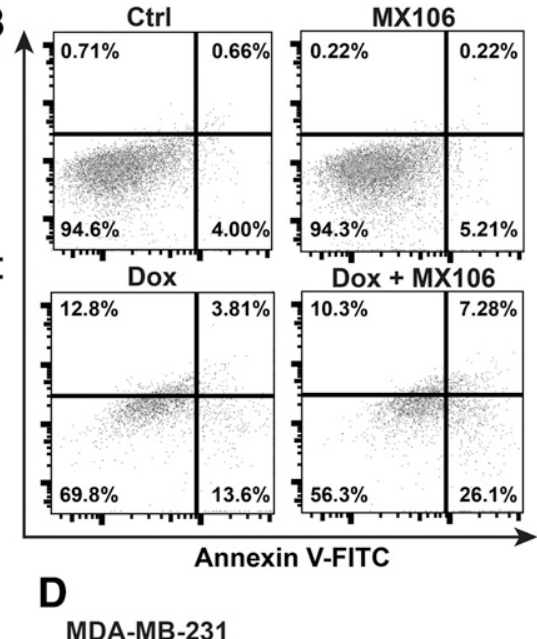

MDA-MB-231

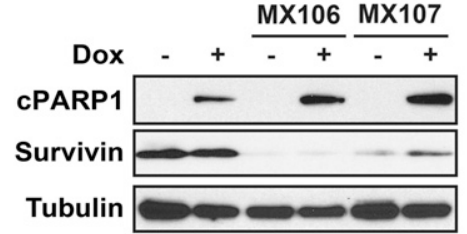

Fig. 2. MX106/MX107 significantly enhances genotoxic drug-induced apoptosis. (A) MDA-MB-231 cells were treated with Dox $(2 \mu \mathrm{g} / \mathrm{ml})$, MX106 $(3 \mu \mathrm{M})$, or in combination. Crystal violet staining was used to determine cell survival at 2 days after treatment. (B) MDA-MB-231 cells were treated with Dox $(0.5 \mu \mathrm{g} / \mathrm{ml})$ and/or MX106 $(2 \mu \mathrm{M})$ and analyzed by flow cytometry after Annexin V-FITC/PI staining. (C and D) HEK293 (C) and MDA-MB-231 (D) cells were treated with etoposide (VP16, $10 \mu \mathrm{M}$ ) or Dox $(2 \mu \mathrm{g} / \mathrm{ml})$ alone or in combination with MX106 $(3 \mu \mathrm{M})$ or MX107 (3 $\mu \mathrm{M})$. Then cells were harvested for immunoblotting with the indicated antibodies. FITC, fluorescein isothiocyanate; PI, propidium iodide. levels also correlated with more advanced breast cancers and metastasis (Li et al., 2017). Using KM-Plotter (Lánczky et al., 2016), we determined the correlation between survivin expression levels with overall survival in 1402 patients with breast cancer. High survivin levels were significantly associated with poor overall survival in patients with breast cancer (hazard ratio, 2.58; 95\% confidence interval, $1.94-3.44 ; P=$ $1.9 \mathrm{e}-11$; Fig. 1A, left). In patients with TNBC, higher survivin expression strongly correlated with shorter relapse-free survival (hazard ratio, 2.19; 95\% confidence interval, 1.34-3.59; $P=0.0014$; Fig. 1A, right). These data suggest that increased survivin plays critical roles in promoting breast cancer progression and relapse.

To determine whether survivin inhibition decreases TNBC cell viability, we treated MDA-MB-231 cells with varying doses of MX106 or MX107 for 24 hours. Both MX106 and MX107 effectively suppressed MDA-MB-231 cell proliferation, with $\mathrm{IC}_{50}$ values around 2 to $3 \mu \mathrm{M}$ (Fig. 1B). Moreover, combining MX106 with Dox significantly enhanced the tumoricidal efficacy of Dox in TNBC cells, compared with Dox treatment alone (Fig. $1 \mathrm{C}$ ). The $\mathrm{IC}_{50}$ value of Dox to MDAMB-231 cells decreased from 31.95 to $1.62 \mathrm{ng} / \mathrm{ml}$, a decrease of almost 20 -fold, suggesting a synergistic effect between these two drugs. To validate this synergism, we determined the CI value for the combination of MX106 and Dox following the reported algorithm (Chou, 2010). We found that the CI of this two-drug combination in MDA-MB-231 cells was 0.016 at $\mathrm{ED}_{50}$ (Fig. 1D; Supplemental Table 1), suggesting a strong synergistic effect between MX106 and Dox. Interestingly, although another survivin inhibitor, YM155 [1-(2-methoxyethyl)2-methyl-3-(pyrazin-2-ylmethyl)-2H-benzo[f]benzimidazole-4,9dione;bromide], showed higher potency in inhibiting MDA-MB-231 cell growth $\left(\mathrm{IC}_{50}=3.7 \mathrm{nM}\right.$; Supplemental Fig. 1A), MX106 showed a substantially enhanced CI when combined with Dox compared with YM155, suggesting a robust synergism between MX106 and Dox in inhibiting MDA-MB-231 cell proliferation (Supplemental
Fig. 1B; Supplemental Table 1). In addition, combination treatment with MX106 also substantially enhanced the tumoricidal effect of Dox in osteosarcoma U2OS cells (Fig. 1E). Moreover, when we combined MX106 with IR for treating MDA-MB-231 cells, an enhanced tumoricidal effect was also observed with the combinatory treatment compared with IR alone (Fig. 1F). All of these results strongly suggest that survivin inhibitors MX106/MX107 could synergize with genotoxic drugs and radiation, resulting in significantly improved antitumor efficacy of these cytotoxic treatments.

Survivin Inhibitors Enhance Genotoxic TreatmentInduced Apoptosis. We found that the combination treatment of MX106 and Dox substantially decreased MDA-MB-231 cell survival, compared with treatment with either MX106 or Dox (Fig. 2A). To determine whether survivin inhibition enhances Dox-induced cancer cell apoptosis, we carried out flow cytometry analysis with propidium iodide/Annexin $\mathrm{V}$ staining in MDA-MB-231 cells treated with MX106, Dox, or in combination. Interestingly, treatment with MX106 alone $(2 \mu \mathrm{M})$ did not significantly increase apoptosis in MDA-MB-231 cells. In contrast, the combination treatment of MX106 with Dox doubled the apoptotic population compared with that by Dox alone (Fig. 2B). Consistent with the flow cytometry data, we also detected significantly increased PARP1 cleavage and caspase 3 activation in cells treated with chemodrug etoposide (VP16) or Dox in combination with either MX106 or MX107, compared with cells treated with Dox alone (Fig. 2, C and D). Meanwhile, we did not observe strong activation of caspase 3 and PARP1 cleavage in cells treated with MX106 or MX107, suggesting that the tumorsuppressive effect of MX106/MX107 on MDA-MB-231 cells we observed likely depends on proliferation inhibition.

MX106/MX107 Diminishes Genotoxic Agent-Induced NF-кB Activation. Our previous studies demonstrated that genotoxic agents, such as Dox and IR, could activate NF- $\kappa$ B, which inhibits genotoxic treatment-induced apoptosis in cancer cells (McCool and Miyamoto, 2012; Wang et al., 
A

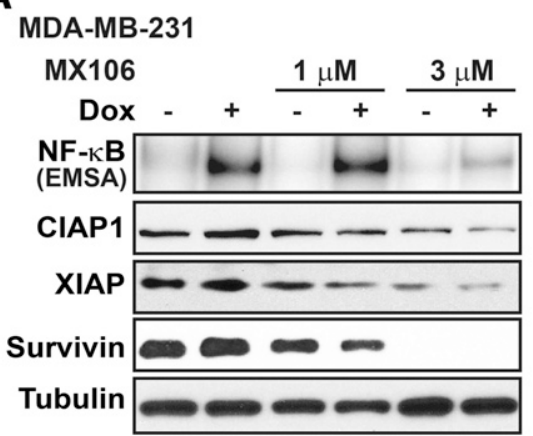

C

U2OS

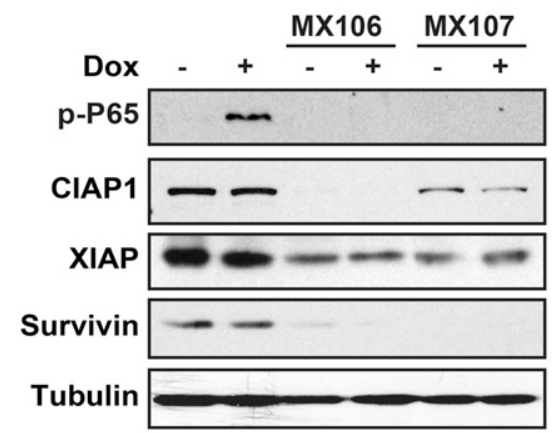

E

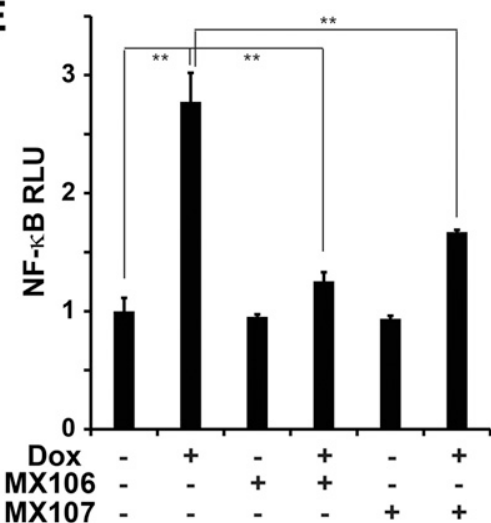

B

HEK293

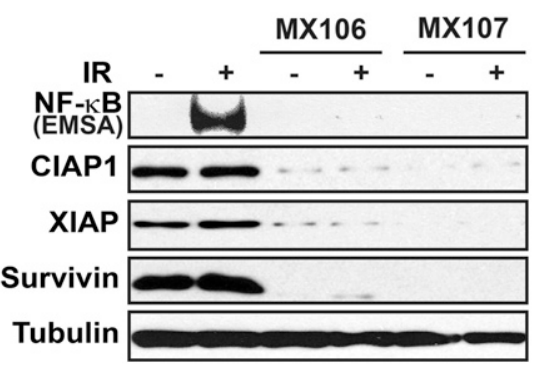

D

HEK293
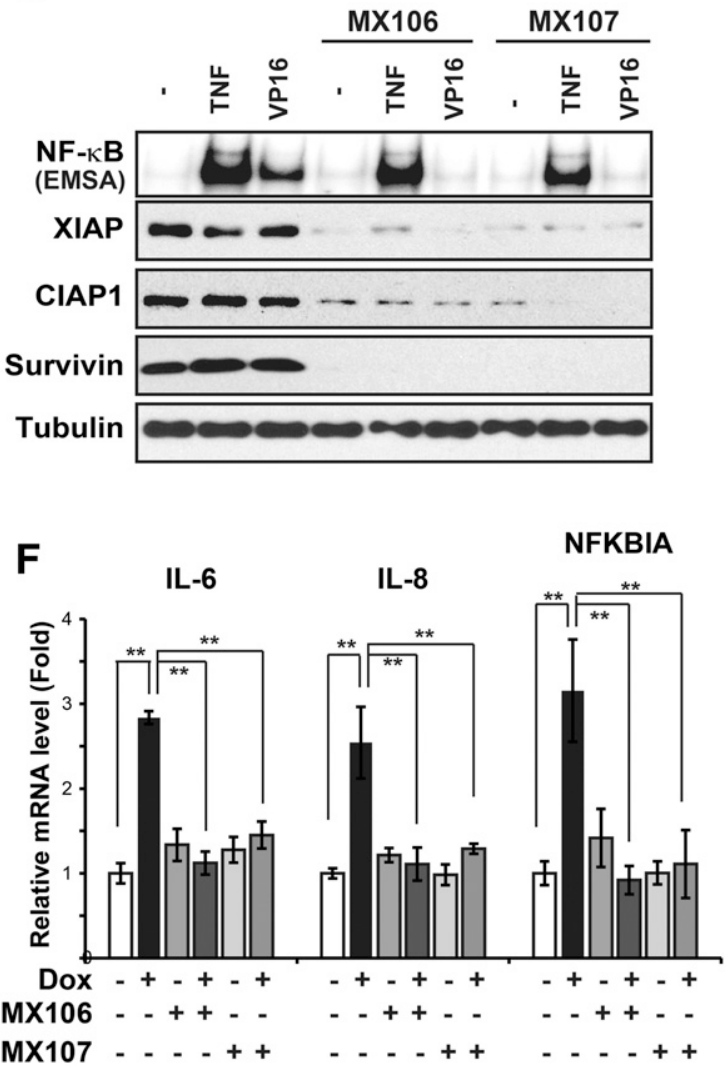

Fig. 3. MX106/MX107 inhibits NF- $\kappa$ B activation by genotoxic agents. (A) MDA-MB-231 cells pretreated with dimethylsulfoxide or increasing doses of MX106 for 12 hours were exposed to Dox $(2 \mu \mathrm{g} / \mathrm{ml})$ for 2 hours as indicated. NF- $\kappa$ B activity was examined by EMSA. Whole cell extracts were analyzed by Western blotting with the indicated antibodies. (B) HEK293 cells were pretreated with dimethylsulfoxide, MX106 (3 $\mu$ M), or MX107 (3 $\mu$ M) for 12 hours. Cells were then exposed to IR (10 Gy) and harvested at 2 hours after treatment. Whole cell extracts were analyzed as in (A). (C) U2OS cells were treated with Dox $(2 \mu \mathrm{g} / \mathrm{ml})$ with or without MX106/MX107 pretreatment as in (B) and analyzed by immunoblotting as indicated. (D) HEK293 cells were treated with TNF $\alpha(10 \mathrm{ng} / \mathrm{ml}, 15$ minutes) or VP16 (10 $\mu \mathrm{M}, 2$ hours) in a setting similar to (B). Whole cell lysates were analyzed accordingly. (E) The transactivity of NF- $\kappa$ B was monitored with NF- $\kappa$ B Luciferase reporter in MDA-MB-231 cells after the indicated treatment. (F) The mRNA levels of IL-6, IL-8, and $\mathrm{I} \kappa \mathrm{B} \alpha$ (NFKBIA) were analyzed by quantitative polymerase chain reaction in MDA-MB-231 cells treated with Dox (2 $\mu \mathrm{g} / \mathrm{ml}), \mathrm{MX} 106$ ( $3 \mu \mathrm{M})$, or MX107 $(3 \mu \mathrm{M})$ alone or in combination as indicated. EMSA, Electrophoretic Mobility Shift Assay; RLU, relative light unit.

2017). We found that cotreatment of MX106 with Dox substantially decreased Dox-induced NF- $\kappa$ B activation (Fig. 3A). This inhibition of genotoxic stress-induced NF- $\kappa$ B is not limited to MDA-MB-231 cells or Dox treatment, since we observed similar inhibition of NF- $\kappa$ B signaling in HEK293 cells treated with IR and in U2OS cells exposed to Dox (Fig. 3, $\mathrm{B}$ and $\mathrm{C}$ ). In these cells, we noticed that along with a dramatic decrease of survivin expression upon MX106/MX107 treatment, the expression of other IAPs, such as cIAP1 and XIAP, also decreased to a varying extent depending on the cell type
(Fig. 3, A-C). XIAP and cIAP1 have been shown to be required for genotoxic $\mathrm{NF}-\kappa \mathrm{B}$ signaling in various cancer cells (Jin et al., 2009; Hinz et al., 2010; Wu et al., 2010). Consistent with this, we observed inhibition of $\mathrm{NF}-\kappa \mathrm{B}$ activation by pretreatment with MX106/MX107 in HEK293 cells stimulated by VP16, which correlated with significantly ; decreased expression of cIAP1, XIAP, and survivin Fig. 3D). In contrast, YM155 treatment did not decrease cIAP1 and XIAP levels in MDA-MB-231 cells, although survivin was substantially suppressed 
A
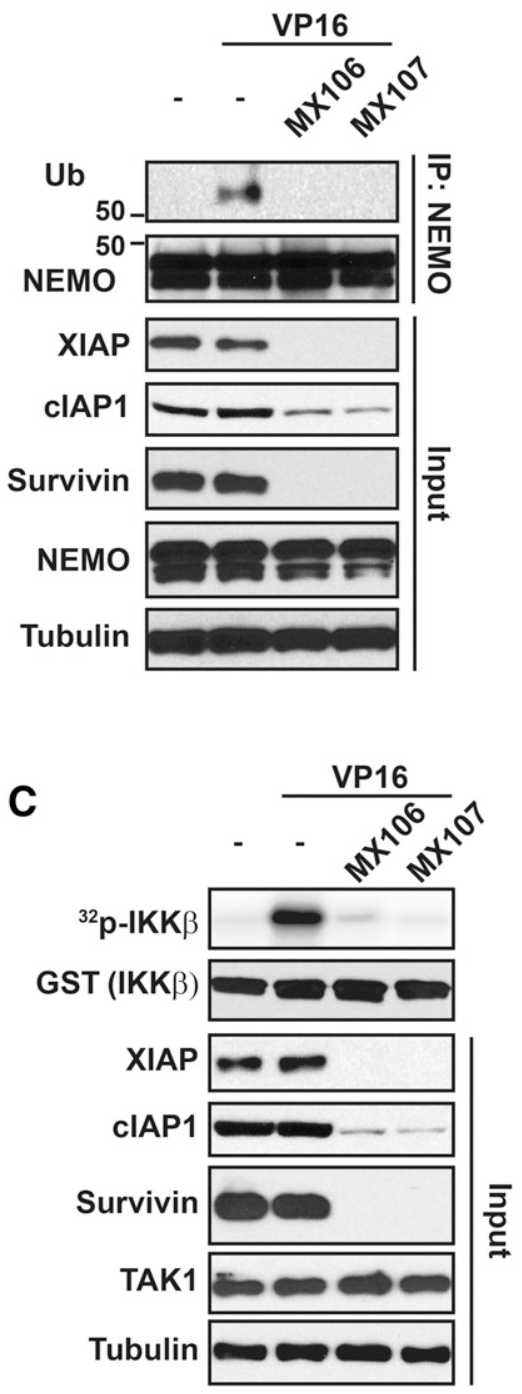

B
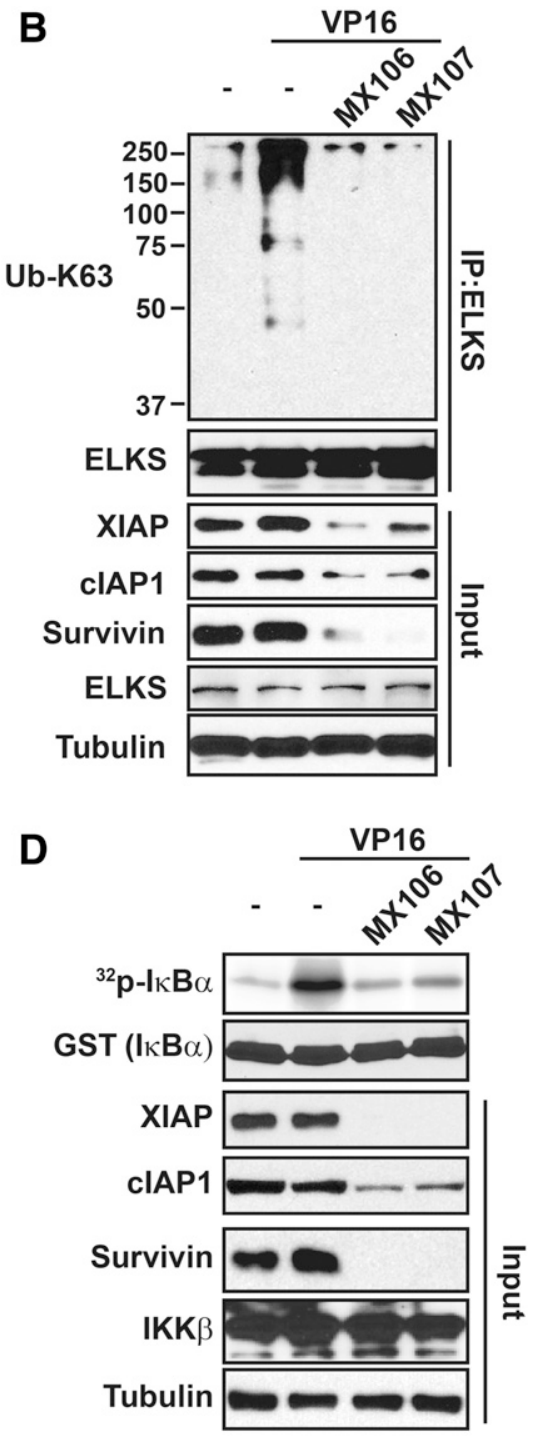

Fig. 4. MX106/MX107 suppresses DNA damage-induced activation of TAK1/IKK by promoting cIAP1/XIAP degradation. (A) HEK293T cells were pretreated with dimethylsulfoxide, MX106 (3 $\mu \mathrm{M})$, or MX107 (3 $\mu \mathrm{M})$ for 12 hours. Cells were then exposed to VP16 (10 $\mu \mathrm{M})$ and harvested at 1 hour after treatment. Whole cell extracts were immunoprecipitated with anti-NEMO, followed by immunoblotting with antibodies as shown. Five percent of whole cell extracts were used as the input control. (B) HEK293T cells were treated as in (A). ELKS were immunoprecipitated by respective antibodies. Immunoprecipitates were blotted by K63 Ub linkage-specific antibody as indicated. Five percent of whole cell lysates as input were analyzed by Western blot as shown. (C) HEK293T cells were treated as in (B). TAK1 kinase activity was determined by an in vitro kinase assay using GST-IKK $\beta$ as substrate. Whole cell extracts were analyzed by immunoblotting as indicated. (D) IKK activity in cells treated as in (C) was measured by a kinase assay using GST-I $\kappa \mathrm{B} \alpha$ as substrate. GST, glutathione $S$-transferase.
(Supplemental Fig. 1C). Meanwhile, Dox-induced NF- $\kappa$ B activation was not inhibited by YM155.

Previous reports showed that SMAC mimetics such as BV6 [(2S)-1-[(2S)-2-cyclohexyl-2-[[(2S)-2-(methylamino)propanoyl] amino $]$ acetyl $]-N-[(2 S)-1-[6-[[(2 S)-2-[[(2 S)-1-[(2 S)-2-c y c l o-$ hexyl-2-[[(2S)-2-(methylamino)propanoyl]amino]acetyl] pyrrolidine-2-carbonyl]amino]-3,3-diphenylpropanoyl]amino]hexylamino]-1-oxo-3,3-diphenylpropan-2-yl]pyrrolidine-2carboxamide] and compound A (Varfolomeev et al., 2007; Vince et al., 2007), which both induce rapid cIAP1 degradation, activate alternative $\mathrm{NF}-\kappa \mathrm{B}$ signaling pathways. We found that treatment with MX106 up to 24 hours did not substantially increase p52 processing, which correlates with incomplete cIAP1 depletion in cells treated with MX106 (Supplemental Fig. 2A). Furthermore, we did not observe an obvious change in classic $\mathrm{NF}-\kappa \mathrm{B}$ activation by tumor necrosis factor $\alpha(\mathrm{TNF} \alpha)$ in cells treated with MX106 or MX107 (Fig. 3D). These data suggest that survivin inhibitor MX106/MX107 predominantly suppresses genotoxic $\mathrm{NF}-\kappa \mathrm{B}$ signaling.

We further validated the impact of survivin inhibitors on genotoxic NF- $\kappa \mathrm{B}$ activation by a reporter assay. Accordingly,
MX106/MX107 significantly inhibited the transactivity of NF- $\kappa$ B in MDA-MB-231 cells treated with Dox (Fig. 3E). Moreover, Dox-induced upregulation of canonical NF- $\kappa$ Btarget genes, such as $\mathrm{I} \kappa \mathrm{B} \alpha$ (NFKBIA), interleukin (IL)-6 (IL6), and IL-8 (CXCL8), was substantially suppressed by MX106/MX107 (Fig. 3F). All of these data strongly support that survivin inhibitor MX106/MX107 could diminish genotoxic agent-induced NF- $\kappa \mathrm{B}$ activation and suppress its downstream target gene transcription, which may play a role in enhancing cancer cell sensitivity to genotoxic treatments and promoting apoptosis.

MX106/MX107 Interferes with Genotoxic NF- $\boldsymbol{B}$ Signaling by Suppressing cIAP1/XIAP-Mediated Ubiquitylation. We previously showed that NEMO monoubiquitylation is essential for NEMO export from the nucleus and subsequent IKK activation in the cytoplasm (Huang et al., 2003; Wu et al., 2006). Further studies showed that cIAP1 is an essential ubiquitin E3 ligase for mediating NEMO monoubiquitylation (McCool and Miyamoto, 2012; Holohan et al., 2013). Since our survivin inhibitors also decreased levels of cIAP1 in cells, we examined whether MX106/MX107 also affects NEMO monoubiquitylation upon genotoxic treatment. Indeed, 
A

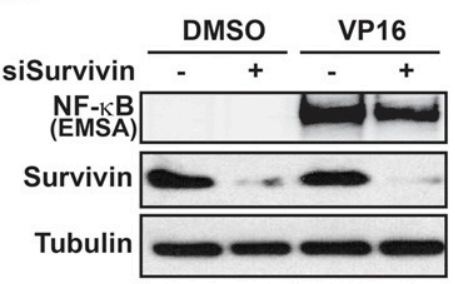

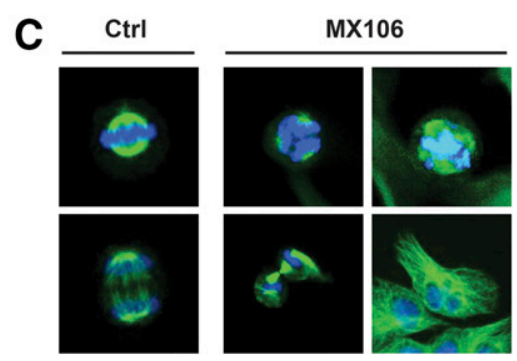

D

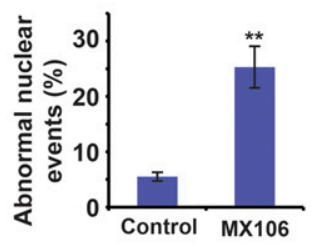

Fig. 5. Antagonizing survivin by MX106 leads to cell cycle arrest and abnormal cell division. (A) Survivin was depleted by small interfering RNA in HEK293T cells. NF- $\kappa$ B activation upon VP16 treatment (10 $\mu \mathrm{M}, 2$ hours) was examined by EMSA as indicated. (B) Cell cycle in control or MX106 treated (3 $\mu \mathrm{M}, 48$ hours) MDA-MB-231 cells was examined by flow cytometry. (C and D) Mitotic cells and cell division were visualized by immunofluorescence staining with anti- $\alpha$-tubulin and $4^{\prime}, 6$-diamidino-2-phenylindole in control or MX106-treated (2 $\mu \mathrm{M}, 48$ hours) MDA-MB-231 cells. Representative abnormal microtubule spindles and aberrant cell division upon MX106 treatment are shown in (C) and are quantified as abnormal nuclear events in (D). EMSA, Electrophoretic Mobility Shift Assay.
NEMO monoubiquitylation was decreased in HEK293 cells treated with VP16 in combination with MX106 or MX107 (Fig. 4A). Consistent with this, we found that VP16induced K63-linked polyubiquitylation of ELKS, another key modulator of genotoxic $\mathrm{NF}-\kappa \mathrm{B}$ signaling (Wang et al., 2017), was also diminished by MX106/MX107 (Fig. 4B). This inhibition of ELKS K63-ubiquitylation is likely due to MX106/MX107-induced downregulation of XIAP, which is also required for ELKS ubiquitylation upon genotoxic stress.

Previous reports have shown that NEMO monoubiquitylation and ELKS K63-ubiquitiylation are essential for TAK1/IKK kinase cascade activation upon genotoxic treatments (Wu et al., 2006; McCool and Miyamoto, 2012; Wang et al., 2017). As shown in Fig. 4, C and D, we observed a dramatically decreased activation of TAK1 and IKK by VP16 in cells cotreated with MX106 or MX107 using in vitro kinase assays. Altogether, these results indicate that the survivin inhibitor MX106/MX107 could suppress DNA damage-induced NF- $\kappa$ B kinase cascade activation by attenuating essential upstream ubiquitylation events.

Survivin Is Dispensable for Genotoxic NF- $\kappa$ B Activation, But Is Essential for Cell Cycle Progression in Cancer Cells. Since it is unclear whether survivin plays a role in mediating $\mathrm{NF}-\kappa \mathrm{B}$ activation by genotoxic treatment, we knocked down survivin with specific small interfering RNA in HEK293 cells and examined NF- $\kappa$ B activation by genotoxic drug VP16. Depletion of survivin had little effect on VP16induced NF- $\kappa$ B activation (Fig. 5A). Similar results were also observed in MDA-MB-231 cells treated with Dox (data not shown). These observations indicate that survivin is not required for effective $\mathrm{NF}-\kappa \mathrm{B}$ activation by genotoxic treatments.

Survivin is a member of the chromosomal passenger complex along with Aurora B, Borealin, and INCEP, which play an essential role in regulating chromosome-microtubule attachment, spindle assembly checkpoint, and cytokinesis during mitosis and cell division (Carmena et al., 2012). Depletion of survivin has been shown to lead to abnormal cell division and mitotic catastrophe (Altieri, 2015). We treated MDA-MB-231 cells with MX106 for 48 hours. In accordance with previous reports (Pennati et al., 2004; Kedinger et al., 2013), depletion of survivin led to cell cycle arrest at the G2/M phase (Fig. 5B). Moreover, aberrant mitotic progression indicated by an increased fraction of polyploid cells with more than 4 N DNA content was observed in MDA-MB-231 cells treated with MX106. This observation is consistent with the essential role of survivin in proper completion of mitosis and cell division. Accordingly, we observed significantly increased abnormal nuclear events, such as enlarged nuclei, misarranged chromosome alignment, failed chromosome segregation, and disrupted microtubule polymerization, in MX106-treated cells (Fig. 5, C and D). All of these data suggest that inhibition of survivin by MX106 directly promotes cell cycle arrest and mitotic catastrophe, which may eventually lead to necrotic and apoptotic cell death in cancer cells (Vitale et al., 2011).

Survivin Inhibitor Sensitize TNBC Tumors to Chemotherapy In Vivo. To determine whether survivin inhibitor can synergize with cytotoxic chemotherapeutics to suppress tumor growth in vivo, we generated an orthotopic TNBC xenograft model by injecting MDA-MB-231LM2 cells into mouse mammary fat pads as we reported previously (Niu et al., 2016). Tumor growth was monitored and tumor-bearing mice were randomly separated into four treatment groups as indicated in Fig. 6A. We found that MX106 alone was able to reduce xenograft tumor progression. Dox treatment led to decreased tumor growth, whereas xenograft tumors soon adapted to the Dox treatment and regained the growth potential after the third injection. Combination treatment of Dox with MX106 showed significantly enhanced tumorsuppressive efficacy than treatment with either agent alone (Fig. 6, A and B). Importantly, no regaining of tumor growth potential was observed after combinatory treatment until the end point, suggesting potential mitigation of acquired resistance to Dox in xenograft tumors. We also observed further decreased lung metastasis in the combination treatment group, compared with the single-agent groups (Fig. 6C).

To validate the efficacy of MX106 in promoting degradation of survivin and other IAPs, we examined the protein lysates extracted from xenograft tumors. As expected, the survivin level was significantly decreased in tumors treated with 
A

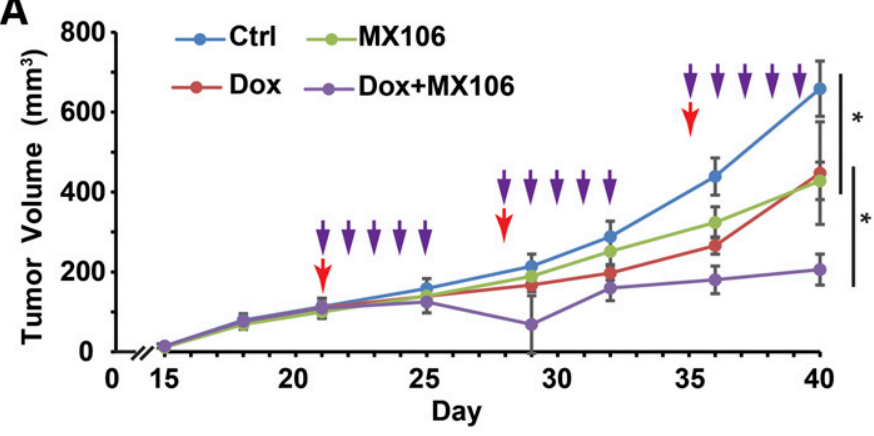

C
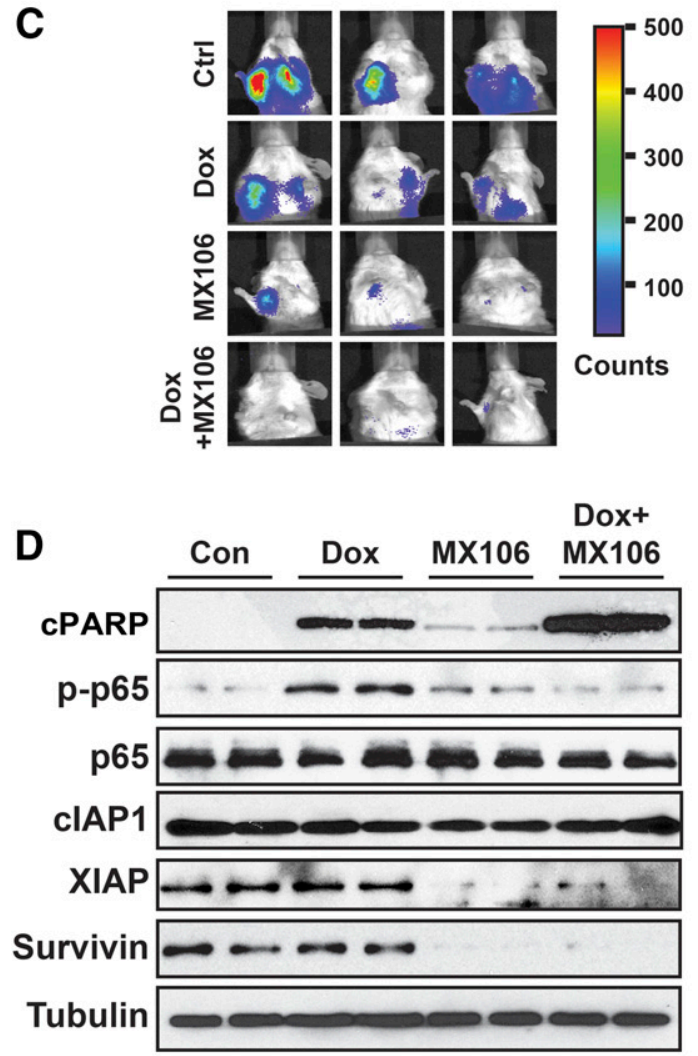

B

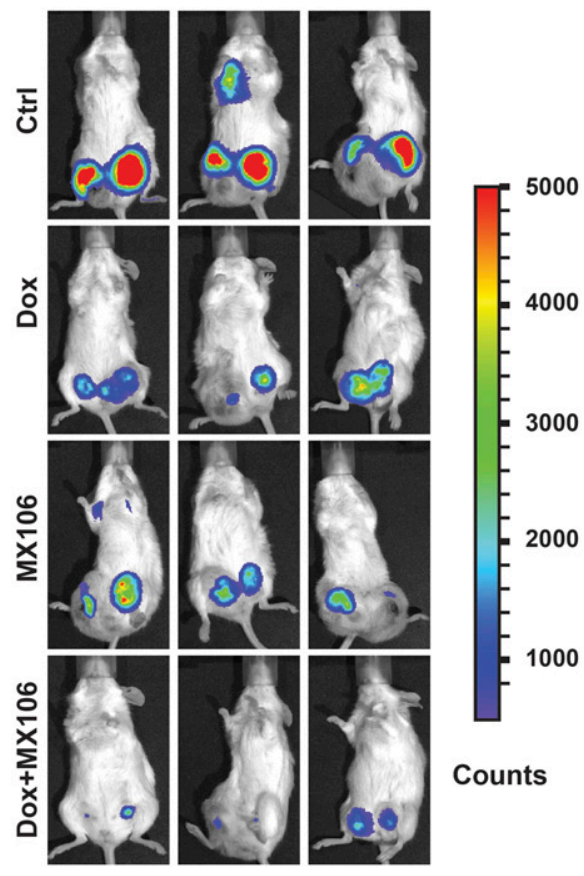

E

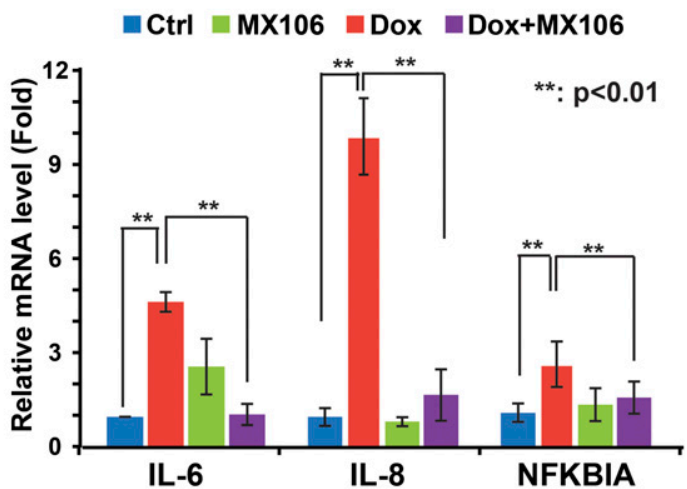

Fig. 6. Survivin inhibitor MX106 shows synergism with Dox treatment in suppressing tumor growth and metastasis in vivo. (A) NSG mice transplanted with MDA-MB-231 LM2 cells $(n=5)$ were treated with phosphate-buffered saline, Dox $(2 \mathrm{mg} / \mathrm{kg})$, MX106 (20 mg/kg), or in combination when xenograft tumor volume reached approximately $100 \mathrm{~mm}^{3}$ as shown. Xenograft tumor growth was monitored and showed as the tumor volume. Red arrows indicate Dox or N.S. treatment; purple arrows indicate MX106 injection. $* P<0.05$. (B) Bioluminescence imaging was performed at the experiment end point to visualize tumor size. (C) Pulmonary tumor outgrowth was monitored by bioluminescent imaging as in (B). (D) Protein samples extracted from xenograft tumors (two/group) were immunoblotted by antibodies against p-P65, p65, cleaved PARP, XIAP, survivin, and tubulin. (E) RNA samples were extracted from tumors and analyzed by quantitative polymerase chain reaction. $* * P<0.01$. N.S., Natural Saline; NSG, NOD scid $\gamma$.

MX106 (Fig. 6D). In parallel, XIAP expression was also decreased in response to MX106 treatment, whereas the change in cIAP1 expression was negligible. Consistent with our observation in vitro, Dox treatment induced robust $\mathrm{NF}-\kappa \mathrm{B}$ activation in tumors, which was substantially decreased in tumors cotreated with MX106. We also observed no substantial increase in NIK level and p52 processing in tumors treated with MX106 (Supplemental Fig. 2B), suggesting that the alternative $\mathrm{NF}-\kappa \mathrm{B}$ signaling was not activated in these tumors. Along with decreased genotoxic $\mathrm{NF}-\kappa \mathrm{B}$ activation, we found increased PARP cleavage in tumors treated with the combination of Dox with MX106, compared with those treated with Dox alone, suggesting increased tumor cell apoptosis (Fig. 6D). In addition,
Dox-induced transcriptional upregulation of IL-6 and IL-8 in TNBC tumors was also significantly decreased by cotreatment with MX106, likely due to suppression of genotoxic $\mathrm{NF}-\kappa \mathrm{B}$ activation (Fig. $6 \mathrm{E}$ ).

\section{Discussion}

Increased survivin levels have been associated with chemoresistance in a variety of malignancies (Coumar et al., 2013; Zheng, 2017). The functions of survivin in regulating apoptosis, autophagy, mitosis, and DNA repair are considered to play major roles in promoting cancer cell survival and evasion from tumoricidal effects of chemotherapeutics and radiation (Grdina et al., 2013). Therefore, survivin has drawn 
significant attention as a target of anticancer agents mitigating drug resistance (Xiao and Li, 2015; Peery et al., 2017). We recently developed both a novel compound with similarity to the SMAC AVPI domain (UC-112) as well as its more potent derivatives (MX106/MX107), which showed high efficiency in promoting survivin degradation and inducing apoptosis in melanoma cells (Chen, 2012; Coumar et al., 2013). Here, we found that the MX106/MX107 suppressed TNBC cell growth and inhibited TNBC xenograft tumor progression in vivo. Although the low dose of MX106/MX107 did not significantly increase apoptosis directly in cancer cells, it effectively arrested cell cycle progression and interrupted cell division, eventually leading to mitotic catastrophe. Furthermore, the survivin inhibitors synergized with genotoxic drugs or IR and dramatically enhanced cancer cell apoptosis in response to cytotoxic treatments. We further showed that degradation of XIAP and/or cIAP1 by MX106/MX107 diminished NF- $\kappa$ B activation induced by these genotoxic agents, which may be responsible, at least in part, for increased drug sensitivity and apoptosis in cancer cells and TNBC xenograft tumors treated with Dox. In line with this notion, survivin inhibitor YM155 failed to decrease cIAP1/XIAP expression and genotoxic $\mathrm{NF}-\kappa \mathrm{B}$ activation in TNBC cells, which may explain its lower synergism with Dox treatment in inhibiting TNBC cell proliferation compared with MX106. These results strongly suggest that the survivin inhibitors MX106 and MX107 may be used in combination with chemotherapeutics, such as Dox, to achieve synergistic tumoricidal effects in treating TNBC.

Anthracycline drugs, such as Dox and epirubicin, are a leading cause of heart failure and irreversible cardiovascular damage in cancer patients after chemotherapy (Brown et al., 2015). The high cardiotoxicity of anthracycline drugs is a major limitation when considering chemotherapeutic regimens for cancer patients with high cardiovascular risk. We found that MX106/MX107 significantly reduced the $\mathrm{IC}_{50}$ value of Dox in cancer cells, which indicates that combining MX106/ MX107 with Dox could substantially reduce the drug dose with comparable efficacy, resulting in a reduced risk of cardiotoxicity in patients. We also observed a similar effect in cancer cells treated with IR in combination of MX106, suggesting their potential application in reducing the radiation dose to treat breast cancer.

Genotoxic treatment-induced NF- $\kappa \mathrm{B}$ activation has been considered as a major mechanism by which cancer cells acquire drug resistance (Zheng, 2017). Our previous studies showed that, in addition to antiapoptotic genes induced by $\mathrm{NF}-\kappa \mathrm{B}$, upregulation and secretion of inflammatory cytokines (i.e., IL-6 and IL-8) may also contribute to a chronic inflammatory microenvironment that enhances the survival and increased invasiveness in cancer cells (Niu et al., 2012, 2016; Wang et al., 2017). MX106/MX107 substantially reduced induction of inflammatory cytokine IL-6 and IL-8 in vitro and in xenograft tumors after Dox treatment. Moreover, the lung metastasis of xenograft tumors was also significantly reduced in xenografted mice treated with Dox in combination with MX106, compared with that in mice treated with Dox or MX106 alone. These data suggest that MX106/MX107mediated suppression of NF- $\kappa \mathrm{B}$ activation by chemotherapeutic drugs not only sensitizes TNBC cells to chemotherapy but could also reduce their metastatic potential.

Previous studies have demonstrated that treatment with SMAC-mimetic compounds with high potency in degrading
cIAP1/2 proteins, such as BV6 and compound A, could stabilize NIK and activate alternative $\mathrm{NF}-\kappa \mathrm{B}$ signaling, thereby upregulating $\mathrm{TNF} \alpha$ (Varfolomeev et al., 2007; Vince et al., 2007). Autocrine and/or paracrine of $\mathrm{TNF} \alpha$ stimulate cancer cell apoptosis in the absence of cIAP1-mediated prosurvival branch of TNF $\alpha$ signaling, which could be further reinforced by increased complex II (RIP1/FADD/caspase 8) formation due to decreased RIP1 ubiquitylation by cIAP1 (Fulda, 2015b). We did not observed alternative NF- $\kappa \mathrm{B}$ activation and induction of apoptosis by MX106/MX107 treatment alone in breast cancer cells, which may be attributable to the relatively low dose we used for combination treatment. High basal p52 levels in MDA-MB-231 cells may also increase the threshold for further enhancing alternative NF- $\kappa \mathrm{B}$ signaling. Furthermore, MX106 and MX107 and their precursor compound UC-112 have been shown to induce survivin degradation with high potency, although they are less effective in inducing cIAP1/2 and XIAP degradation (Xiao et al., 2015). Nevertheless, the tumoricidal effect and caspase activation in melanoma cells by MX106/MX107 and their precursor UC-112 may involve alternative NF- $\kappa$ B activation and $\mathrm{TNF} \alpha / \mathrm{RIP} 1$-induced apoptotic signaling (Wang and Li, 2014; Xiao et al., 2015), which warrants further investigation.

Survivin expression is abundant in embryonic stem cells during fetal development. It also plays critical roles in the homeostasis of adult stem/progenitor cells, such as hematopoietic stem cells and neuronal stem cells (Altieri, 2015). Moreover, previous reports showed that survivin overexpression initiated hematopoietic stem cell-driven malignancies in mice (Small et al., 2010) and promoted survival of glioma stem-like cells during gliomagenesis (Guvenc et al., 2013). In accordance, high survivin levels are associated with poor survival in stem cell-driven tumors, such as acute leukemia and gliomas. Therefore, it is plausible that survivin has important roles in regulating cancer stem-like cell/cancerinitiating cell behavior. In addition to their importance in cancer initiation and relapse, cancer stem-like cells are also a major source of drug resistance (Oskarsson et al., 2014). Our data indicate that degradation of cIAP1/XIAP by MX106/ MX107 could suppress genotoxic NF- $\kappa$ B activation, resulting in reduced drug resistance. Meanwhile, directly targeting survivin by MX106/MX107 may decrease the cancer stemlike cell population, which could also contribute to increased drug sensitivity and mitigation of drug resistance.

In summary, we found that survivin inhibitor MX106/ MX107 significantly increased the therapeutic potency of Dox in treating TNBC cells. Combined treatment with Dox and MX106 showed superior tumor-suppressive efficacy, compared with Dox or MX106 alone, in a TNBC MDA-MB231 xenograft model. Mechanistically, MX106/MX107induced degradation of cIAP1 and/or XIAP attenuated $\mathrm{NF}-\kappa \mathrm{B}$ activation by chemotherapeutic drugs and radiation, which sensitized cancer cells to cytotoxic treatment. Combining MX106/MX107 or other SMAC-mimetic compounds with anthracycline drugs may significantly improve their therapeutic efficacy, which may enable physicians to treat cancer patients with a lower dose of anthracycline and thereby reduce treatment-associated cardiotoxicity. Inhibiting survivin by a variety of approaches has been shown to induce apoptosis in cancer cells (Altieri, 2015; Xiao and Li, 2015; Peery et al., 2017). Although the lower dose of MX106/MX107 did not directly induce apoptosis, it is sufficient for causing cell cycle 
arrest and promoting mitotic catastrophe. Moreover, the MX106/MX107-dependent inhibition of genotoxic NF- $\kappa$ B activation could further enhance cytotoxic treatment-induced apoptosis. Several SMAC mimetics, predominantly antagonizing cIAP1, cIAP2, and XIAP, are under evaluation in clinical trials (Fulda, 2015a,b). Meanwhile, survivin inhibitor YM155 has also been tested as a single agent or in combination with other anticancer agents for treating various solid tumors and blood cancers (Peery et al., 2017). Unlike YM155, MX106/MX107 is not sensitive to P-glycoprotein pumpmediated drug efflux (Xiao et al., 2015), indicating a reduced drug resistance prospect in cancer cells. Therefore, our novel survivin inhibitor MX106/MX107 may be able to harness the therapeutic benefit from inhibiting oncogenic activity of survivin in promoting cancer cell survival and mitosis, as well as cIAP1/XIAP-facilitated genotoxic NF- $\kappa \mathrm{B}$ activation, leading to synergistic tumor-suppressive efficacy when used to in combination with genotoxic agents.

\section{Acknowledgments}

We thank Dr. Junming Yue (University of Tennessee Health Science Center) for providing valuable reagents used in this study.

\section{Authorship Contributions}

Participated in research design: Wang, Fan, Li, Z.-H. Wu. Conducted experiments: Wang, Zhang, Mani, Z. Wu, Z.-H. Wu. Contributed new reagents or analytic tools: $\mathrm{Z}$. Wu, Li. Performed data analysis: Wang, Z. Wu, Fan, Li, Z.-H. Wu.

Wrote or contributed to the writing of the manuscript: Wang, Fan, Li, Z.-H. Wu.

\section{References}

Altieri DC (2015) Survivin - the inconvenient IAP. Semin Cell Dev Biol 39:91-96.

Baldwin AS (2012) Regulation of cell death and autophagy by IKK and NF-кB: critical mechanisms in immune function and cancer. Immunol Rev 246:327-345.

Bianchini G, Balko JM, Mayer IA, Sanders ME, and Gianni L (2016) Triple-negative breast cancer: challenges and opportunities of a heterogeneous disease. Nat Rev Clin Oncol 13:674-690.

Brown SA, Sandhu N, and Herrmann J (2015) Systems biology approaches to adverse drug effects: the example of cardio-oncology. Nat Rev Clin Oncol 12:718-731.

Carmena M, Wheelock M, Funabiki H, and Earnshaw WC (2012) The chromosomal passenger complex (CPC): from easy rider to the godfather of mitosis. Nat Rev Mol Cell Biol 13:789-803.

Chen ZJ (2012) Ubiquitination in signaling to and activation of IKK. Immunol Rev 246:95-106.

Chou TC (2010) Drug combination studies and their synergy quantification using the Chou-Talalay method. Cancer Res 70:440-446.

Coumar MS, Tsai FY, Kanwar JR, Sarvagalla S, and Cheung CH (2013) Treat cancers by targeting survivin: just a dream or future reality? Cancer Treat Rev $\mathbf{3 9}$ 802-811.

Foulkes WD, Smith IE, and Reis-Filho JS (2010) Triple-negative breast cancer. N Engl J Med 363:1938-1948.

Fu K, Sun X, Wier EM, Hodgson A, Liu Y, Sears CL, and Wan F (2016) Sam68/ KHDRBS1 is critical for colon tumorigenesis by regulating genotoxic stressinduced NF-кB activation. elife 5: e15018.

Fulda S (2015a) Promises and challenges of Smac mimetics as cancer therapeutics. Clin Cancer Res 21:5030-5036.

Fulda S (2015b) Smac mimetics as IAP antagonists. Semin Cell Dev Biol 39:132-138.

Garg H, Suri P, Gupta JC, Talwar GP, and Dubey S (2016) Survivin: a unique target for tumor therapy. Cancer Cell Int 16:49.

Grdina DJ, Murley JS, Miller RC, Mauceri HJ, Sutton HG, Li JJ, Woloschak GE, and Weichselbaum RR (2013) A survivin-associated adaptive response in radiation therapy. Cancer Res 73:4418-4428.

Guvenc H, Pavlyukov MS, Joshi K, Kurt H, Banasavadi-Siddegowda YK, Mao P, Hong C, Yamada R, Kwon CH, Bhasin D, et al. (2013) Impairment of glioma stem cell survival and growth by a novel inhibitor for Survivin-Ran protein complex. Clin Cancer Res 19:631-642.

Hinz M, Stilmann M, Arslan SC, Khanna KK, Dittmar G, and Scheidereit C (2010) A cytoplasmic ATM-TRAF6-cIAP1 module links nuclear DNA damage signaling to ubiquitin-mediated NF-кB activation. Mol Cell 40:63-74.

Holohan C, Van Schaeybroeck S, Longley DB, and Johnston PG (2013) Cancer drug resistance: an evolving paradigm. Nat Rev Cancer 13:714-726.

Huang TT, Wuerzberger-Davis SM, Wu ZH, and Miyamoto S (2003) Sequential modification of NEMO/IKKgamma by SUMO-1 and ubiquitin mediates NF-kappaB activation by genotoxic stress. Cell 115:565-576.

Jin H-S, Lee D-H, Kim D-H, Chung J-H, Lee S-J, and Lee TH (2009) cIAP1, cIAP2, and XIAP act cooperatively via nonredundant pathways to regulate genotoxic stress-induced nuclear factor-kappaB activation. Cancer Res 69:1782-1791.
Kedinger V, Meulle A, Zounib O, Bonnet ME, Gossart JB, Benoit E, Messmer M, Shankaranarayanan P, Behr JP, Erbacher P, et al. (2013) Sticky siRNAs targeting survivin and cyclin B1 exert an antitumoral effect on melanoma subcutaneous xenografts and lung metastases. BMC Cancer 13:338.

Lánczky A, Nagy Á, Bottai G, Munkácsy G, Szabó A, Santarpia L, and Győrffy B (2016) miRpower: a web-tool to validate survival-associated miRNAs utilizing expression data from 2178 breast cancer patients. Breast Cancer Res Treat 160: $439-446$.

Li S, Wang L, Meng Y, Chang Y, Xu J, and Zhang Q (2017) Increased levels of LAPTM4B, VEGF and survivin are correlated with tumor progression and poor prognosis in breast cancer patients. Oncotarget 8:41282-41293.

Mabb AM, Wuerzberger-Davis SM, and Miyamoto S (2006) PIASy mediates NEMO sumoylation and NF-kappaB activation in response to genotoxic stress. Nat Cell Biol 8:986-993.

McCool KW and Miyamoto S (2012) DNA damage-dependent NF-кB activation: NEMO turns nuclear signaling inside out. Immunol Rev 246:311-326.

Mitra A, Mishra L, and Li S (2015) EMT, CTCs and CSCs in tumor relapse and drugresistance. Oncotarget 6:10697-10711.

Nakanishi C and Toi M (2005) Nuclear factor-kappaB inhibitors as sensitizers to anticancer drugs. Nat Rev Cancer 5:297-309.

Niu J, Shi Y, Tan G, Yang CH, Fan M, Pfeffer LM, and Wu ZH (2012) DNA damage induces NF-кB-dependent microRNA-21 up-regulation and promotes breast cancer cell invasion. J Biol Chem 287:21783-21795.

Niu J, Shi Y, Xue J, Miao R, Huang S, Wang T, Wu J, Fu M, and Wu ZH (2013) USP10 inhibits genotoxic NF-кB activation by MCPIP1-facilitated deubiquitination of NEMO. EMBO J 32:3206-3219.

Niu J, Xue A, Chi Y, Xue J, Wang W, Zhao Z, Fan M, Yang CH, Shao ZM, Pfeffer LM, et al. (2016) Induction of miRNA-181a by genotoxic treatments promotes chemotherapeutic resistance and metastasis in breast cancer. Oncogene 35: $1302-1313$

Oskarsson T, Batlle E, and Massagué J (2014) Metastatic stem cells: sources, niches, and vital pathways. Cell Stem Cell 14:306-321.

Peery RC, Liu JY, and Zhang JT (2017) Targeting survivin for therapeutic discovery: past, present, and future promises. Drug Discov Today 22:1466-1477.

Pennati M, Binda M, Colella G, Zoppe' M, Folini M, Vignati S, Valentini A, Citti L, De Cesare M, Pratesi G, et al. (2004) Ribozyme-mediated inhibition of survivin expression increases spontaneous and drug-induced apoptosis and decreases the tumorigenic potential of human prostate cancer cells. Oncogene 23:386-394

Ryan B, O'Donovan N, Browne B, O'Shea C, Crown J, Hill AD, McDermott E, O'Higgins N, and Duffy MJ (2005) Expression of survivin and its splice variants survivin-2B and survivin-DeltaEx3 in breast cancer. $\mathrm{Br} J$ Cancer 92: $120-124$

Singh A and Settleman J (2010) EMT, cancer stem cells and drug resistance: an emerging axis of evil in the war on cancer. Oncogene 29:4741-4751.

Small S, Keerthivasan G, Huang Z, Gurbuxani S, and Crispino JD (2010) Overexpression of survivin initiates hematologic malignancies in vivo. Leukemia 24: $1920-1926$

Stilmann M, Hinz M, Arslan SC, Zimmer A, Schreiber V, and Scheidereit C (2009) A nuclear poly(ADP-ribose)-dependent signalosome confers DNA damage-induced IkappaB kinase activation. Mol Cell 36:365-378.

Varfolomeev E, Blankenship JW, Wayson SM, Fedorova AV, Kayagaki N, Garg P, Zobel K, Dynek JN, Elliott LO, Wallweber HJA, et al. (2007) IAP antagonists induce autoubiquitination of c-IAPs, NF-kappaB activation, and TNFalphadependent apoptosis. Cell 131:669-681.

Vince JE, Wong WW-L, Khan N, Feltham R, Chau D, Ahmed AU, Benetatos CA Chunduru SK, Condon SM, McKinlay M, et al. (2007) IAP antagonists target cIAP1 to induce TNFalpha-dependent apoptosis. Cell 131:682-693.

Vitale I, Galluzzi L, Castedo M, and Kroemer G (2011) Mitotic catastrophe: a mechanism for avoiding genomic instability. Nat Rev Mol Cell Biol 12 $385-392$.

Wang J and Li W (2014) Discovery of novel second mitochondria-derived activator of caspase mimetics as selective inhibitor of apoptosis protein inhibitors. J Pharmacol Exp Ther 349:319-329.

Wang W, Mani AM, and Wu ZH (2017) DNA damage-induced nuclear factor-kappa B activation and its roles in cancer progression. J Cancer Metastasis Treat 3:45-59.

Wu ZH and Miyamoto S (2007) Many faces of NF-kappaB signaling induced by genotoxic stress. J Mol Med (Berl) 85:1187-1202.

Wu ZH, Shi Y, Tibbetts RS, and Miyamoto S (2006) Molecular linkage between the kinase ATM and NF-kappaB signaling in response to genotoxic stimuli. Science 311:1141-1146

Wu ZH, Wong ET, Shi Y, Niu J, Chen Z, Miyamoto S, and Tergaonkar V (2010) ATMand NEMO-dependent ELKS ubiquitination coordinates TAK1-mediated IKK activation in response to genotoxic stress. Mol Cell 40:75-86.

Xiao M and Li W (2015) Recent advances on small-molecule survivin inhibitors. Curr Med Chem 22:1136-1146.

Xiao M, Wang J, Lin Z, Lu Y, Li Z, White SW, Miller DD, and Li W (2015) Design, synthesis and structure-activity relationship studies of novel survivin inhibitors with potent anti-proliferative properties. PLoS One 10:e0129807.

Zheng HC (2017) The molecular mechanisms of chemoresistance in cancers. Oncotarget 8:59950-59964.

Address correspondence to: Zhao-Hui Wu, Department of Pathology and Laboratory Medicine, Center for Cancer Research, University of Tennessee Health Science Center, 19 South Manassas Street, Memphis, TN 38163. E-mail: zwu6@uthsc.edu; or Wei Li, Department of Pharmaceutical Sciences, University of Tennessee Health Science Center, 881 Madison Avenue, Memphis, TN 38163. E-mail: wli@uthsc.edu 